\title{
Mouse Strain and Sex-Dependent Differences in Long-term Behavioral Abnormalities and Neuropathologies after Developmental Zika Infection
}

\author{
Abigail Snyder-Keller, ${ }^{1,2}$ Laura D. Kramer, ${ }^{1,2}$ Steven Zink, ${ }^{1}$ and Valerie J. Bolivar ${ }^{1,2}$ \\ ${ }^{1}$ Wadsworth Center, New York State Department of Health, Albany, New York 12201, and ${ }^{2}$ Department of Biomedical Sciences, University of Albany School \\ of Public Health, Albany, New York 12214
}

Exposure of the developing fetus to Zika virus (ZIKV) results in a set of brain abnormalities described as the congenital Zika syndrome. Although microcephaly is the most obvious outcome, neuropathologies, such as intracranial calcifications and polymicrogyria, can occur in the absence of microcephaly. Moreover, the full impact of exposure on motor, social, and cognitive skills during development remains uncharacterized. We examined the long-term neurobehavioral consequences of neonatal ZIKV exposure in four genetically divergent inbred mouse strains (C57BL/6J, 129S1/SvImJ, FVB/NJ, and DBA/2J). Male and female mice were infected on postnatal day 1, considered comparable with exposure late in the second trimester of humans. We demonstrate strain differences in early susceptibility to the virus and the time course of glial reaction in the brain. These changes were associated with strain- and sex-dependent differences in long-term behavioral abnormalities that include hyperactivity, impulsiveness, and motor incoordination. In addition, the adult brains of susceptible mice exhibited widespread calcifications that may underlie the behavioral deficits observed. Characterization of the neuropathological sequelae of developmental exposure to the Zika virus in different immunocompetent mouse strains provides a foundation for identifying genetic and immune factors that contribute to long-term neurobehavioral consequences in susceptible individuals.

Key words: behavioral deficits; calcifications; congenital Zika syndrome; developmental exposure; neuropathology; Zika virus

\section{Significance Statement}

Developmental Zika virus (ZIKV) infection is now known to cause brain abnormalities in infants that do not display microcephaly at birth, and the full impact of these more subtle neuropathologies has yet to be determined. We demonstrate in a mouse model that long-lasting behavioral aberrations occur after developmental ZIKV exposure. We compare four divergent mouse strains and find that the effects of Zika infection differ greatly between strains, in terms of behavioral changes, sex differences, and the intracranial calcifications that develop in the brains of susceptible mice. These findings provide a foundation for identifying susceptibility factors that lead to the development of abnormal behaviors secondary to ZIKV infection early in life.

\section{Introduction}

With the discovery of congenital abnormalities resulting from prenatal exposure to the Zika virus (ZIKV), ZIKV can now be added to the list of traditional TORCH pathogens that, when present during pregnancy, can result in severe teratogenic effects (Coyne and

Received 0ct. 23, 2018; revised March 25, 2019; accepted April 14, 2019.

Author contributions: A.S.-K., L.D.K., and V.J.B. designed research; A.S.-K. and S.Z. performed research; A.S.-K., S.Z., and V.J.B. analyzed data; A.S.-K. wrote the first draft of the paper; A.S.-K. and V.J.B. edited the paper; A.S.-K., L.D.K., S.Z., and V.J.B. wrote the paper.

This work was supported by a Wadsworth Center Grant to A.S.-K., L.D.K., and V.J.B. We thank the Wadsworth Center's Veterinary Sciences staff for the excellent care they provided for the mice; Kevin Manley for assistance with genotyping; and Dr. Linda Toth for helpful comments on the manuscript.

The authors declare no competing financial interests.

Correspondence should be addressed to Abigail Snyder-Keller at Abigail.snyder-keller@health.ny.gov.

https://doi.org/10.1523/JNEUROSCI.2666-18.2019

Copyright $\odot 2019$ the authors
Lazear, 2016). Recent studies have led to the realization that the "congenital Zika syndrome" includes neuropathologies that occur independent of microcephaly (Melo et al., 2016; Aragao et al., 2017; Chimelli et al., 2017; Honein et al., 2017). For example, intracranial calcifications (ICCs), polymicrogyria, and ventricular enlargement have been reported in nonmicrocephalic infants (Aragao et al., 2017; Chimelli et al., 2017). This has led to concerns that a large number of ZIKV-exposed infants may present with neurobehavioral deficits that are not immediately apparent in the neonatal period (Kapogiannis et al., 2017). Moreover, ZIKV exposure beyond the first trimester may result in more subtle brain abnormalities that escape detection by conventional imaging modalities. Thus, broader animal models of developmental ZIKV infection, both in terms of timing and genetic background, are necessary to reveal the full spectrum of neurobehavioral deficits possible, and to begin to identify factors that determine susceptibility. 
Because of the initial scare regarding the microcephaly observed in ZIKV-exposed infants, the first rodent models used early gestational exposure (comparable with first trimester) to target cortical neurogenesis and reproduce the microcephaly (Li et al., 2016; Miner et al., 2016). However, exposure later during brain development has the potential to interfere with the development of brain connectivity that underlies more complex behaviors. The first postnatal week in mice is considered comparable with the third trimester in humans in terms of brain development, and recent studies have highlighted the susceptibility of postnatal mice to ZIKV infection (Manangeeswaran et al., 2016; Fernandes et al., 2017; van den Pol et al., 2017). However, these studies did not include a comprehensive analysis of behavioral deficits later in life. Because neonatal mice cannot mount the same interferon-based immune response to the virus, the postnatal approach circumvents the use of interferon receptor $\mathrm{KO}$ mice that have become the standard for adult ZIKV exposure (Lazear et al., 2016; Rossi et al., 2016). Here, we examined the neurobehavioral consequences of neonatal ZIKV exposure in four genetically divergent inbred mouse strains (C57BL/6J, 129S1/SvImJ, FVB/NJ, and DBA/2J). These four mouse strains are from different branches of the mouse family tree and differ in their susceptibility to viral, bacterial, and fungal infection, with many of the genetic differences that underlie their divergent immune responses already identified (Petkov et al., 2004; Sellers et al., 2012). We report strain- and sex-dependent differences in long-term behavioral abnormalities related to early susceptibility to ZIKV, the time course of glial reaction, and the development of neuropathologies, such as calcifications.

\section{Materials and Methods}

\section{Animals}

All mice used in these studies were the offspring of C57BL/6J (B6), 129S1/ SvImJ (129S1), FVB/NJ (FVB), and DBA/2J (DBA) mice obtained from The Jackson Laboratory. Breeder pairs were housed in clear microisolater cages $(38 \times 19 \times 14 \mathrm{~cm})$ and maintained on a 12:12 h light/dark cycle (lights on 7:00 A.M.) in a temperature $\left(68^{\circ} \mathrm{F}-72^{\circ} \mathrm{F}\right)$ and humidity $(50 \%-$ $55 \%$ ) controlled room in the Wadsworth Center facility. Food (LabDiet 5P76 Irradiated RMH3000) and water were available ad libitum. A total of 9 B6 litters (average litter size, 7.4 pups), 14 129S1 litters (average litter size, 6.6 pups), 7 FVB litters (average litter size, 11 pups), and 4 DBA litters (average litter size, 5.5 pups) were used. After weaning on postnatal day (P) 28, littermates were housed in same strain and sex groups of 2-4 per cage. Behavioral testing was conducted during the light phase of the light/dark cycle, using adult animals (P60-P90). Both sexes were included in neuroanatomical and behavioral tests. All procedures had prior approval by the Wadsworth Center Institutional Animal Care and Use Committee.

Postnatal ZIKV injections. On P1, mice of both sexes received a single subcutaneous injection of ZIKV strain PRVABC59 (GenBank KU501215.1) at the nape of the neck via $27 \mathrm{~g} / 0.5 \mathrm{ml}$ syringe (10e3 PFU in $0.05 \mathrm{ml}$ ). PRVABC59 is a well-characterized ZIKV strain that was isolated during the current outbreak in the Americas (Puerto Rico), and is used at low passage. Virus stock was prepared in Vero cell culture and frozen in $1.0 \mathrm{ml}$ aliquots in BA-1 diluent with 20\% FBS. For each litter to be injected, virus is thawed and diluted 1:10 in vehicle (PBS with $1 \%$ FBS) to obtain the $10 \mathrm{e} 3$ concentration (in $0.05 \mathrm{ml}$ ). This dose was chosen to produce a short symptomatic period, followed by recovery and maximal survival (Manangeeswaran et al., 2016). Controls were littermates injected subcutaneously with the vehicle and given toe-clips to differentiate them from their ZIKV-injected littermates. Mice were weighed weekly (on P1, P7, P14, P21, P28, P35) and observed daily (twice per day during the symptomatic period). Except for DBA mice, 2-7 infected pups and 1 or 2 control littermates per inbred strain were killed at $7 \mathrm{~d}$ intervals to determine the time course of virus expression and distribution within the brain. Due to the infrequent litters and small litter size of DBA mice, these were primarily saved for later behavioral analyses. At each time point, half of each brain was fixed in 4\% PFA for neuroanatomical analysis, and the other half-brain, as well as spleen, liver, and kidneys, were homogenized and frozen at $-80^{\circ} \mathrm{C}$ until processing for qRT-PCR to measure viral burden.

\section{Behavioral tests}

Three behavioral tests (open field, elevated zero maze, rotarod) were selected to measure exploratory behavior, anxiety-like behavior, and motor incoordination. Beginning at P60, behavioral experiments were conducted in order from least (open field) to most (rotarod) aversive, separated by 1 week, at approximately the same time of day (afternoon). Uninjected mice were added to control groups as needed to maintain sample size, and were not different from vehicle-injected littermate controls in these tests.

Open field. For evaluation of exploratory activity in the open field, each mouse was placed in the center of a completely dark open field chamber $(42 \mathrm{~cm} \times 42 \mathrm{~cm} \times 30 \mathrm{~cm})$ and allowed to move freely for $15 \mathrm{~min}$. Data from the session were acquired using Digiscan 16-beam automated activity monitors (AccuScan Instruments).

Elevated zero maze. The elevated zero maze is a circular maze consisting of two open and two closed sections (TSE Systems), designed to measure anxiety-related behavior (Shepherd et al., 1994). Each mouse is placed in the middle of one of the closed sections and allowed to explore for $5 \mathrm{~min}$. The time spent in open and closed sections and the latency to fully traverse an open section to enter the other closed portion were recorded.

Rotarod. A rotarod apparatus (AccuScan Instruments) was used to measure motor coordination and balance, using a constant-acceleration protocol (4-40 rpm for a max of $180 \mathrm{~s}$ ). The mice were tested on 3 consecutive days, with 3 trials/d with an intertrial interval of 20-30 min. A final score for each mouse was calculated as the average of the two longest times they were able to stay on the beam.

\section{Brain analyses}

Immunostaining. Immersion-fixed (4\% PFA) half-brains of ZIKVinfected mice killed during the first month after infection were left in $4 \%$ PFA for $48 \mathrm{~h}$, followed by permeation in $15 \%$ sucrose $(>8 \mathrm{~h})$. Brains were then embedded in egg yolk hardened by exposure to formalin $(4 \mathrm{~h})$, and returned to sucrose before sectioning frozen on a sliding microtome in the sagittal plane $(40 \mu \mathrm{m})$. The brains of adult mice were fixed by intracardiac perfusion of $4 \%$ PFA, followed by postfixation $(20 \mathrm{~h})$, permeation in $15 \%$ sucrose, and sectioning in the coronal plane $(35 \mu \mathrm{m})$. Immunostaining was done free-floating using the $\mathrm{ABC}$-peroxidase procedure (Vector Labs). After rinsing in PBS, and blocking with 5\% normal goat serum (NGS) in $0.2 \%$ Triton in PBS, sections were incubated in rabbit anti-ZIKV antibodies (Absolute Antibody; 1:500 in 0.1\% Triton $/ 2 \% \mathrm{NGS} / \mathrm{PBS}$ ) overnight at $4^{\circ} \mathrm{C}$. After rinsing, sections were incubated for $1 \mathrm{~h}$ in biotinylated anti-rabbit antibodies (Vector Labs; 1:200 in $0.2 \%$ Triton $/ 2 \% \mathrm{NGS} / \mathrm{PBS}$ ), rinsed again, and then incubated for $1.5 \mathrm{~h}$ in $\mathrm{ABC}$ peroxidase solution. After rinsing, sections were reacted in $0.05 \%$ $\mathrm{DAB} / 0.25 \%$ nickel ammonium sulfate $/ 0.0015 \% \mathrm{H}_{2} \mathrm{O}_{2}$ for $2 \mathrm{~min}$, rinsed, and mounted onto chrom-alum gelatin-coated slides. After dehydration and light counterstaining with cresyl violet, coverslips were applied using Micromount (Surgipath). Other antibodies used were calcium-binding adapter molecule 1 (Iba-1; 1:1250; Wako Chemicals), GFAP protein (1: 100; Incstar), and cleaved caspase-3 (CC3; 1:500; Cell Signaling Technology), using the same immunostaining protocol. Immunostained sections were viewed on an Olympus BX60 microscope, and images of cortex, hippocampus, and cerebellum collected using National Institutes of Health ImageJ software. Quantification of Iba-1 immunostaining was done on four nonoverlapping $1200 \mu \mathrm{m} \times 1600 \mu \mathrm{m}$ cortical fields taken from at least two sections per mouse. Images were thresholded and the area occupied by staining obtained in ImageJ, then averaged to obtain a final score.

Fluoro-Jade (FJ) staining. Sections were mounted and dried onto chrom-alum-coated slides, and stained according to the protocol of Schmued and Hopkins (2000) using a $30 \mathrm{~min}$ incubation in $0.0004 \%$ FJ-B. Sections were viewed under epifluorescence and images of two 

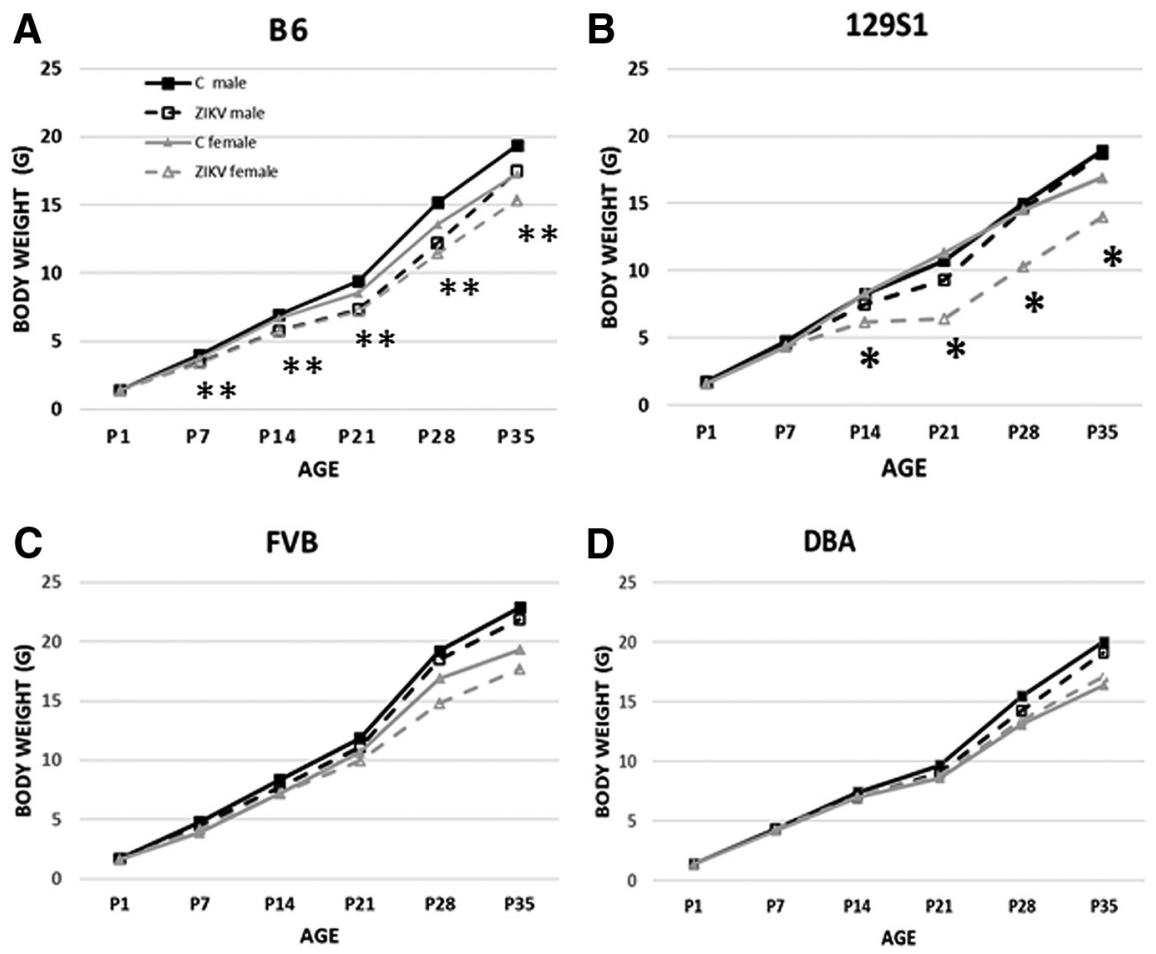

Figure 1. Body weights at weekly intervals for the first 5 weeks, for each strain. Black represents males. Gray represents females. Dotted lines indicate ZIKV-treated. Data were analyzed for each strain separately, using a two-way ANOVA (treatment $X$ sex), followed by Tukey post hoc tests. $A, B 6$ mice displayed a significant main effect of treatment beginning at P7 (P7: $F_{(1,59)}=$ 17.995, $p<0.0001 ; \mathrm{P} 14: F_{(1.57)}=33.709, p<0.0001 ; \mathrm{P} 21: F_{(1.52)}=32.374, p<0.0001 ; \mathrm{P} 28: F_{(1,52)}=24.555, p<0.0001$; P35: $\left.F_{(1,47)}=15.62, p=0.0003\right)$. $B$, Among 12951 mice, only females exhibited weight loss beginning on P14 (P14: $F_{(1,41)}=$ $\left.5.683, p=0.0218 ; \mathrm{P} 21: F_{(1,41)}=16.898, p=0.0002 ; \mathrm{P} 28: F_{(1,37)}=11.046, p=0.002 ; \mathrm{P} 35: F_{(1,28)}=4.925, p=0.0347\right) . p$ values comparing ZIKV-treated and control FVB $(\boldsymbol{C})$ and DBA $(\boldsymbol{D})$ mice at the age they were most divergent (P28) were 0.07 (FVB) and $0.642(\mathrm{DBA}) .{ }^{* *} p<0.05$, for both sexes of ZIKV-treated B6 mice compared with controls of the same strain, age, and sex. ${ }^{*} p<$ 0.05 , for ZIKV-treated $129 S 1$ females compared with controls of the same strain, age, and sex. N values: B6 males (10 C, 22 ZIKV), B6 females (12 C, 19 ZIKV), 129 S1 males (11 C, 10 ZIKV), 129 S1 females (10 C, 16 ZIKV), FVB males (13 C, 10 ZIKV), FVB females (8 C, 26 ZIKV), DBA males (8 C, 10 ZIKV), DBA females (6 C, 6 ZIKV). $N$ values were slightly reduced by the end of 5 weeks due to attrition. C, Controls.

nonoverlapping $600 \mu \mathrm{m} \times 800 \mu \mathrm{m}$ cortical fields collected per mouse. Images were converted to 32-bit, inverted, and thresholded to obtain a count of $\mathrm{FJ}^{+}$cells in each field, then averaged.

$P C R$. Viral burden in the mouse brain, spleen, liver, and kidneys was assessed by qRT-PCR (Lanciotti et al., 2008). Basically, mouse organs were homogenized in diluent containing $20 \%$ FBS, $50 \mu \mathrm{g}$ of streptomycin per milliliter, $50 \mathrm{U}$ of penicillin, and $2.5 \mu \mathrm{g}$ of amphotericin B per milliliters in PBS in a Retsch Mixer Mill set to 24 cycles/s for $3 \mathrm{~min}$. The tubes were then centrifuged for $3 \mathrm{~min}$ at $12,000 \mathrm{rpm}$ and the supernatant removed. Sample RNA was extracted with Magmax Viral isolation kit (Ambion) on a MagMax Express 96 Magnetic particle processor according to the manufacturer's protocol. For MagMax extraction, a total of 50 $\mu$ l of homogenized sample RNA was extracted by the robotic workstation according to the manufacturer's instructions. The extracted RNA was eluted in a total volume of $50 \mu \mathrm{l}$ of elution buffer for direct use in the multiplex assay. To quantitate ZIKV in these organs, Vero cells with known ZIKV titer were diluted in a 10-fold serial dilution to be used as standards in the assay. All work was performed in a BSL-3 facility, all samples were maintained in biosafety cabinets, and sealed rotors were used to prevent exposure to potential aerosols.

The qRT-PCR was set up following the protocol of the qScript XLT One-Step qRT-PCR Toughmix kit (Quanta Biosciences). The cycling conditions were as follows: $5 \mathrm{~min}$ at $50^{\circ} \mathrm{C}$ followed by $30 \mathrm{~s}$ at $95^{\circ} \mathrm{C}$, then 40 cycles of alternating $95^{\circ} \mathrm{C}$ for $10 \mathrm{~s}$ and $60^{\circ} \mathrm{C}$ for $1 \mathrm{~min}$. All analysis was performed using the SDS software version 2.0.6 (Applied Biosystems). The limits of detection are $250 \mathrm{PFU} / \mathrm{g}$ for brain and $500 \mathrm{PFU} / \mathrm{g}$ for all other tissues (Lanciotti et al., 2008).
Nonsuppressive silver staining and quantification of calcifications. Every 12th section was mounted on chrom-alum-coated slides and stained with H\&E for survey of the regional distribution of calcifications. Thereafter, fiber staining of selected sections was accomplished using a technique developed by Lund and Westrum (1966), which modified the original Nauta-Gygax procedure by omitting the pretreatment steps that suppress staining of intact fibers. Briefly, sections previously mounted onto slides were incubated in $1.5 \%$ silver nitrate for $45 \mathrm{~min}$, followed by $1 \mathrm{~min}$ incubations in ammoniacal silver and in Nauta-Gygax reducer. After dehydration and application of coverslips, sections were viewed on a BX60 microscope (Olympus), and images collected using NIH ImageJ software.

A semiquantitative analysis of the ICCs was performed on H\&E-stained sections (every 12th section through the brain). Each of 12 brain regions (rostral cortex, caudal cortex, striatum, septum, hippocampus, thalamus, fasciculus retroflexus, midbrain, pons, cerebellum, corpus callosum, and anterior commissure) was examined where present, and assigned a score of $0.5,1,2$, or 3 based on the number and size of ICCs observed. A score of 0.5 reflected a few scattered ICCs, 1 for larger or more numerous ICCs, and 2 when ICCs occupied a large part (up to 50\%) of that region in any section. A score of 3 was only given when the region was nearly full with ICCs; this only occurred in the cerebellum. The total score for each mouse was then compared with the total distance traveled in the open field test.

\section{Statistical analyses}

Open field, elevated zero maze, and rotarod data were analyzed separately for each inbred strain by two-way ANOVA with treatment (ZIKV or control) and sex (male or female) as the two independent variables. No more than 3 males and 3 females were used from any one litter. In the case of body weight, due to attrition, each day was analyzed separately by two-way ANOVA with treatment and sex as the two independent variables. To further examine treatment differences, Tukey's Honest Significant Difference post hoc tests were used. Spearman correlations were used to determine the relationship between behavioral measures and the amount of ICCs. Viral load, microglia, and FJ-B staining in 129S1 ZIKV-infected mice were analyzed by two-way ANOVA with sex (male or female) and age (P7, P14, P21, or P28) as the two independent variables. Sex differences in FJ-B staining in 129S1-infected mice were then analyzed by $t$ tests at each age. The level of significance was set for $p<0.05$. All statistical procedures were completed using StatView 5.0 software (SAS Institute).

\section{Results}

Weight loss and symptoms occur 2 weeks after infection and vary by strain

Following subcutaneous ZIKV (PRVABC59 strain) infection on $\mathrm{P} 1$, all neonates were accepted by the dams, and no early mortality occurred. For the first $10 \mathrm{~d}$, ZIKV-treated mice of all four strains gained weight and appeared normal (Fig. 1). Body weights analyzed by two-way ANOVA revealed a significant main effect of treatment beginning at $\mathrm{P} 7 \mathrm{in} \mathrm{B} 6$ mice $\left(\mathrm{P} 7, F_{(1,59)}=17.995, p<\right.$ $0.0001 ; \mathrm{P} 14, F_{(1,57)}=33.709, p<0.0001 ; \mathrm{P} 21, F_{(1,52)}=32.374$, $p<0.0001 ; \mathrm{P} 28, F_{(1,52)}=24.555, p<0.0001 ; \mathrm{P} 35, F_{(1,47)}=15.62$, 
$p=0.0003)$. Among 129 S1 mice, only females exhibited weight loss beginning on P14 (P14, $F_{(1,41)}=5.683, p=0.0218$; P21, $F_{(1,41)}=16.898, p=0.0002 ; \mathrm{P} 28, F_{(1,37)}=11.046, p=0.002 ; \mathrm{P} 35$, $\left.F_{(1,28)}=4.925, p=0.0347\right)$. Symptoms were not observed until after P12 and were noticeably different between strains. ZIKVtreated mice of the 129S1 and B6 strains began to show motor symptoms, such as loss of balance and ataxia on or after P12. The most affected mice were observed to fall to the side and occasionally have seizures, and a few progressed to full hindlimb paralysis that required euthanasia. DBA mice exhibited few motor symptoms, although one was observed to have a seizure. Notably, ZIKV-treated FVB mice did not exhibit symptoms at any age, and only a few exhibited slower weight gain. Although the most severely affected ZIKV-treated mice had to be killed, $>85 \%$ of each strain recovered and continued to gain weight. At the time of behavioral testing (P60), ZIKV-treated B6 and 129S1 mice often remained smaller than their control littermates, with the most affected as low as $68 \%$ of control body weight. At no time did the vehicle-injected mice exhibit any of the symptoms displayed by ZIKV-treated mice.

\section{Brain ZIKV infection and microglial activation vary between strains}

Brains of mice were examined at weekly intervals after injection with ZIKV on P1. Infection of neurons was evident at P7, the earliest time point analyzed (Fig. 2). ZIKV immunoreactivity was considerable in the cerebral cortex of B6 and 129S1 mice (Fig. $2 A, B)$, often localized more to the caudal than rostral cortex. ZIKV-immunoreactive neurons were also present in the hippocampus (Fig. 2C) and cerebellum (Fig. 2D), and scattered infected cells were present elsewhere in the brain. ZIKVimmunoreactive neurons were present in FVB and DBA brains at P7, but were nearly absent by P14. In contrast, in B6 and 129S1 brains, ZIKV infection increased between P7 and P14 but was reduced at P21 and nearly undetectable at P28 (data not shown). Control brains were negative for ZIKV immunostaining (Fig. 2B, last column). ZIKV presence in ZIKV-treated mice was confirmed by real-time qRT-PCR in the other half of the same brains. Fig. 2E illustrates the increase in ZIKV RNA from P7 to P14 in B6 and $129 \mathrm{~S} 1$ brains, and the lower levels obtained in FVB and DBA brains. Although too few mice were killed at these early ages to reliably examine sex differences in all strains, individual males and females are plotted. Peripheral organs (liver, spleen, kidney) had lower ZIKV levels than did brain (Fig. 2-1, available at https://doi.org/10.1523/JNEUROSCI.2666-18.2019.f2-1). ZIKV RNA in littermate controls $(n=12$ examined distributed between strains, sexes, and time points) was at or below the limit of detection.

Strain-dependent differences in glial activation after ZIKV infection were evidenced by increased immunostaining for Iba-1 (microglia) and GFAP (astrocytes) (Fig. 3). Increased Iba-1 immunostaining was present at P7 in ZIKV-infected B6 and FVB (Fig. 3A) brains compared with controls (Fig. 3A, last column). Microglial activation, defined as Iba-1-immunoreactive cells having amoeboid rather than ramified morphology (see insets in P14 images), was intense at P14 in 129S1 and B6 mice. In contrast, in P14 FVB brains microglia had already returned to a resting (ramified) morphology characteristic of controls, and minimal activation was observed in DBA brains. At P21 and P28, microglial activation was still strong in B6 and 129S1 mice, but only small nodules of activated microglia were present in FVB mice. Moreover, in B6 and 129S1 mice, microglial activation at P14 and P21 extended throughout the brains, despite the fact that
ZIKV-infected neurons were found primarily in cortex, hippocampus, and cerebellum. Increased GFAP immunostaining (Fig. 3B) was observed in ZIKV-treated mice of all strains at P14, compared with controls (Fig. 3B, insets). ZIKV-exposed B6 and 129S1 mice, but not FVB and DBA, also exhibited an increase in immunoreactivity for CC3, peaking at P14 (Fig. 3C) compared with controls (Fig. 3C, insets), indicating apoptosis in regions (cortex, hippocampus, cerebellum) that contained numerous ZIKV-positive cells.

The differences in weight gain between male and female ZIKV-treated mice of the 129S1 strain led us to probe sex differences in neuronal and glial reaction to the virus. As seen in Figure $2 E$, no obvious differences in the viral load were detected between males and females of this strain (ANOVA, $F=0.488, p=0.4895$ ). Examination of microglial activation at each developmental time point also revealed no differences (Fig. 4A), confirmed by quantification of the density of Iba-1 immunoreactivity in the cortex of these mice (Fig. $4 B$; ANOVA, $F=1.66 \times 10^{-6}, p=0.999$ ). FJ staining to identify dying cells revealed numerous $\mathrm{FJ}^{+}$cells at $\mathrm{P} 14$ and P21, particularly in cortex (Fig. 4C). Quantification of the numbers of $\mathrm{FJ}^{+}$cells revealed a significant increase in female brains (main effect of sex, ANOVA, $F=8.402, p=0.0079$ ). This effect was largely due to an increase at P14 (Fig. $4 D ; t=4.653, p=$ $0.0035)$, at which age all of the mice analyzed had comparably high levels $(>10 \mathrm{e} 6)$ of ZIKV RNA.

\section{Behavioral testing}

Beginning at 2 months of age (P60), mice were tested behaviorally, starting with open field activity. Both male and female ZIKVinfected B6 mice exhibited hyperactivity in the open field compared with same-sex B6 controls (ANOVA main effect of treatment, $F_{(1,48)}=24.596, p<0.0001$; Fig. 5). For the 129S1 strain, there were significant effects of treatment $\left(F_{(1,34)}=7.509\right.$, $p=0.0097)$ and sex $\left(F_{(1,34)}=5.561, p=0.0243\right)$, as well as a significant treatment $\times$ sex interaction $\left(F_{(1,34)}=6.723, p=\right.$ $0.0139)$, indicating that females were more hyperactive after neonatal ZIKV infection. No statistically significant differences between control and ZIKV-infected FVB and DBA mice were observed.

When tested in the elevated zero maze, generally considered a test for anxiety (Shepherd et al., 1994), both male and female ZIKV-infected B6 mice exhibited increased time in the open portions relative to same strain and sex controls (ANOVA main effect of treatment, $F_{(1,48)}=40.039, p<0.0001$; Fig. 6). Only female $129 \mathrm{~S} 1$ mice were significantly different from same-sex controls on this test (ANOVA main effect of sex, $F_{(1,34)}=6.44$, $p=0.0159$; treatment $\times$ sex interaction, $F_{(1,34)}=4.896, p=$ $0.0337)$. Indeed, none of the control $129 S 1$ mice and none of the male ZIKV-treated 129S1 mice left the closed portion of the maze in which they were initially placed, whereas $40 \%$ of the ZIKVtreated 129S1 females traversed the open portion to enter the other enclosed portion of the maze. Fully $100 \%$ of ZIKV-treated male B6 mice crossed to the other side, compared with $57 \%$ of control males, whereas for females no difference was observed ( $87 \%$ of ZIKV-treated crossed compared with $73 \%$ of controls). FVB and DBA mice exhibited no differences in behavior in the elevated zero maze due to ZIKV exposure. Thus, neonatal ZIKV exposure reduced anxiety in the elevated zero maze in a strainand sex-dependent manner.

In the rotarod test for motor coordination, both male and female ZIKV-treated B6 mice exhibited significant reductions in performance compared with same strain and sex controls (ANOVA main effect of treatment, $F_{(1,48)}=12.415, p=0.0009$; 


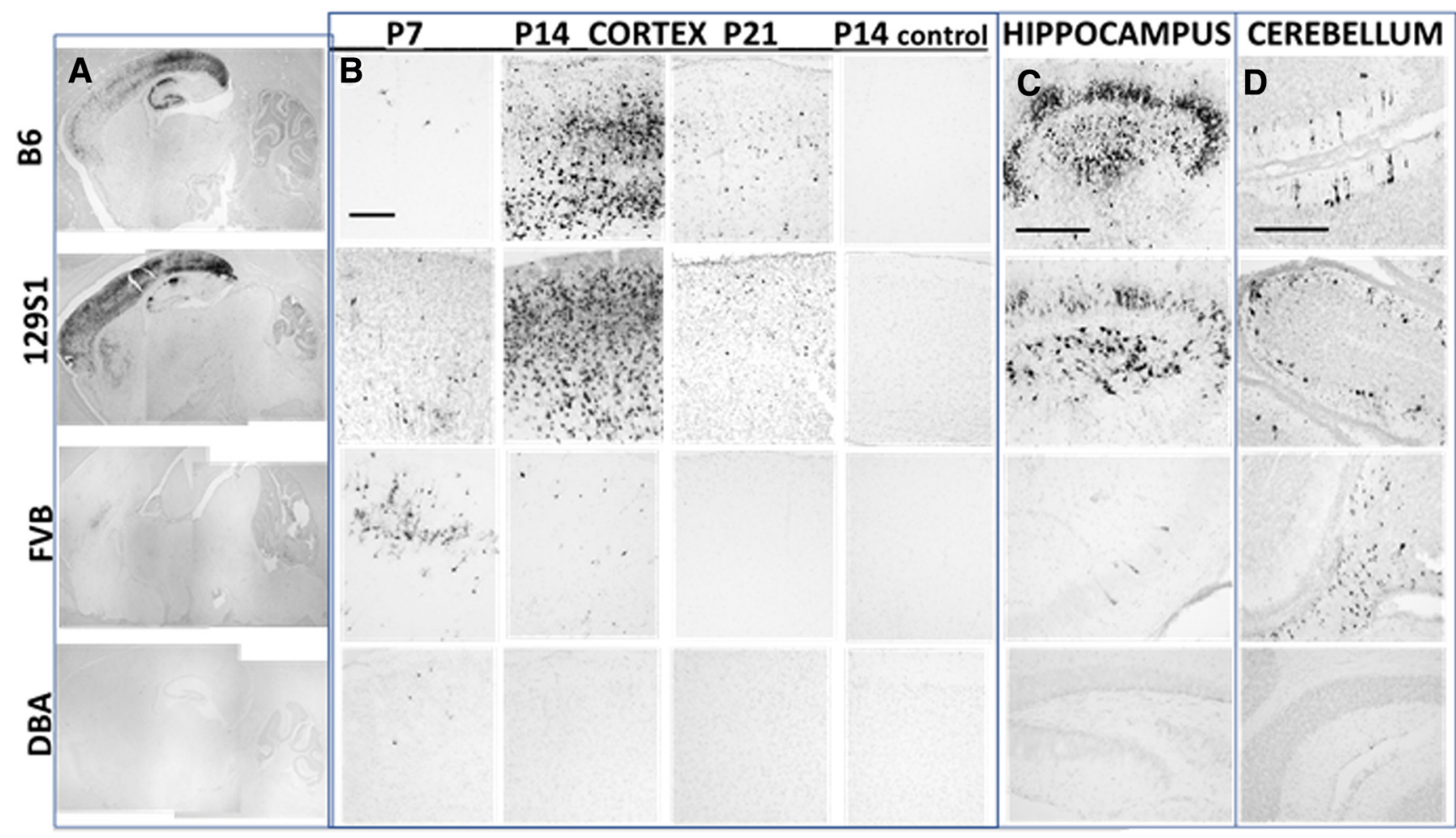

$\mathbf{E}$ B6 $129 \mathrm{~S} 1=\mathrm{FVB} \equiv \mathrm{DBA}$

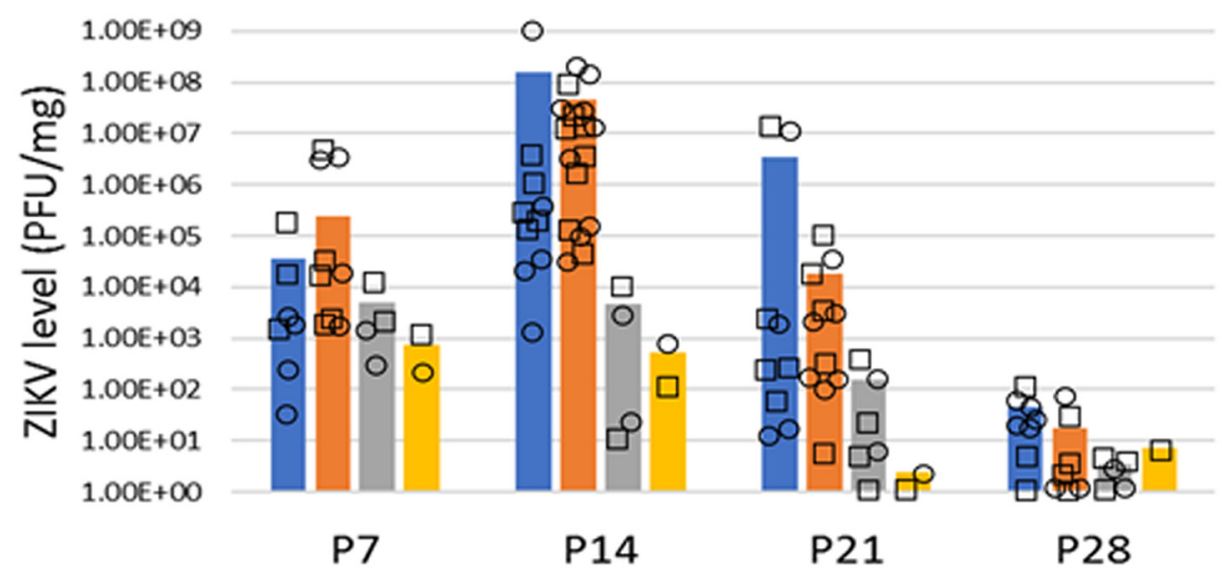

Figure 2. ZIKV in the brain. Immunostaining for ZIKV, in representative brain sections from mice of different strains at P7, P14, and P21. A, Low-magnification images of sagittal sections from all 4 strains; images that follow in each row are from the same strain. $\boldsymbol{B}$, Images from cortex at the 3 ages, with control mice (P14) of the 4 strains shown in the last column. Cortex images span approximately two-thirds of cortical thickness (pial surface at top), taken from caudal cortex. ZIKV immunoreactivity also shown in P14 hippocampus $(\boldsymbol{C})$ and cerebellum (D). Some sections were lightly counterstained with cresyl violet. Images shown are from female mice. Except for DBAs, images shown are representative of at least 2 males and 2 females per strain. Scale bars, $200 \mu \mathrm{m}$. $\boldsymbol{E}$, ZIKV levels in brain measured by PCR ( $n=4-17$ per bar, except for DBAs, for which $n=1$ or 2 at each age). Bars indicate the means. Squares represent individual male mice. Circles represent individual female mice. For ZIKV levels in peripheral tissues, see Figure 2-1 (available at https://doi.org/10.1523/JNEUROSCI.2666-18.2019.f2-1).

Fig. 7). For the $129 \mathrm{~S} 1$ strain, there was a significant main effect of $\operatorname{sex}\left(F_{(1,32)}=5.435, p=0.0262\right)$, but treatment did not have an effect on performance ( $p=0.3018)$. Although some of the hyperactive ZIKV-treated 129S1 females were severely affected, others performed as well as controls, resulting in no overall difference. For FVB mice, there was a significant main effect of sex $\left(F_{(1,40)}=7.031, p=0.0114\right)$, but treatment had no effect on performance $(p=0.5053)$. For the DBA strain, there was a significant main effect of treatment $\left(F_{(1,27)}=17.453, p=0.0003\right)$ and a significant interaction between treatment $\times \operatorname{sex}\left(F_{(1,27)}=\right.$ $13.115, p=0.0012$ ), indicating that ZIKV-treated DBA females fell from the rod faster than control DBA females. Interestingly, whereas mice that exhibited elevated open field activity tended to be those that also spent more time in the open portions of the zero maze, performance on the rotarod appeared unrelated to the other two behaviors.

\section{Neuropathological analyses of adult mice}

Examination of the brains of ZIKV-infected mice after the completion of behavioral testing $(\geq \mathrm{P} 90)$ revealed numerous calcified foci. These were occasionally apparent as white patches on the surface of the cortex after removal of the brains (Fig. 8A). Complete sectioning of each brain, followed by $\mathrm{H} \& \mathrm{E}$ or $\mathrm{H} \& \mathrm{E}$ plus silver staining, revealed calcifications up to $1 \mathrm{~mm}^{2}$ in size that 


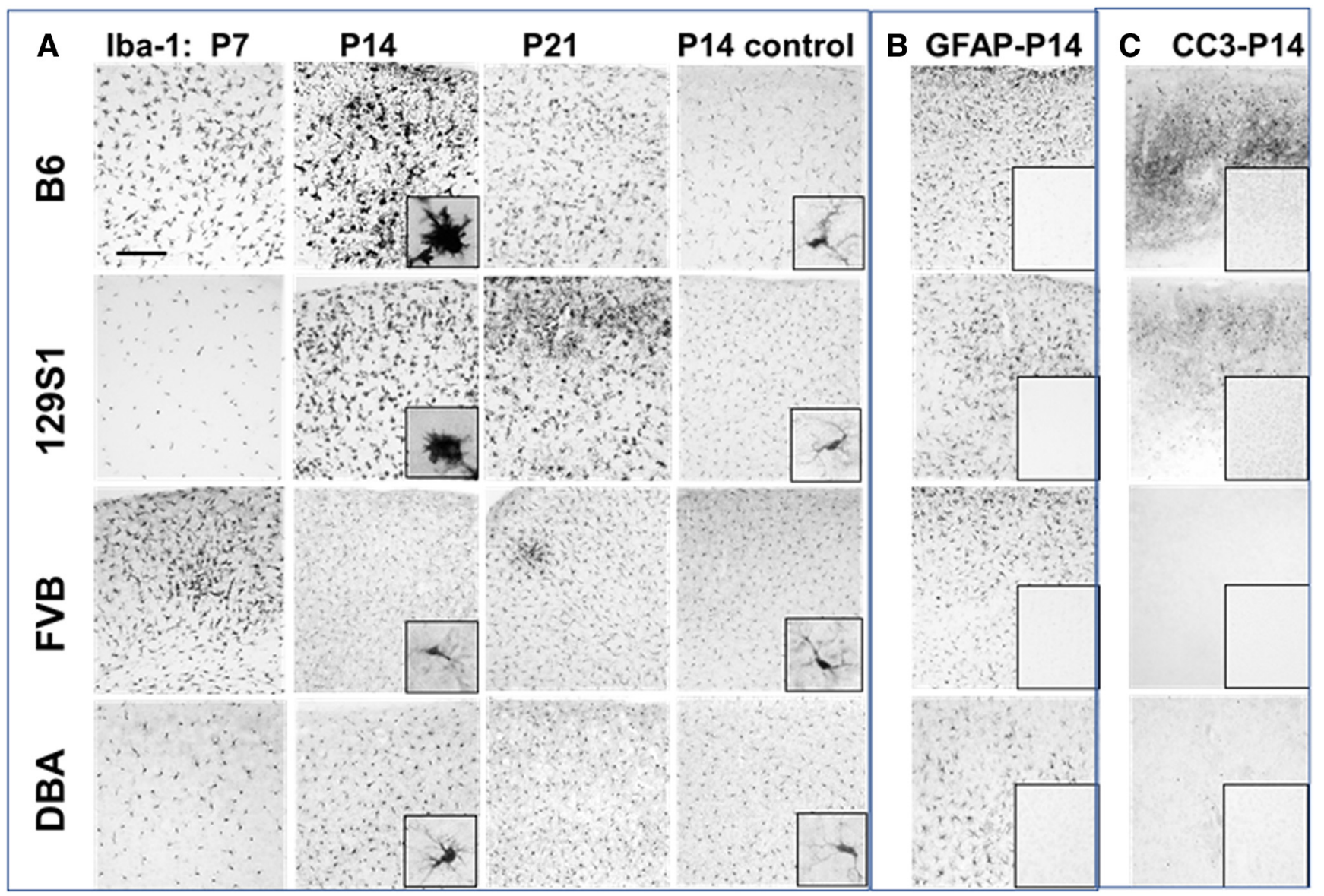

Figure 3. Glial reactivity and apoptosis in the cortex of ZIKV-exposed mice. Immunostaining for Iba-1, GFAP, and CC 3 in representative brain sections from mice of different strains. $A$, Iba-1 immunostaining for microglia illustrates intense microglial activation at P14 in B6 and 12951 brains, which persists at least until P21. Early activation occurs in FVB brains, reduced by P14. Iba-1 images from cortex of control mice of the 4 strains are shown in the last column. Insets in P14 images represent high-magnification views of Iba-1 microglia to illustrate morphology. B, GFAP immunostaining in cortex of the 4 strains at P14. Images at bottom right corner of each are from corresponding controls (same magnification). C, Immunostaining for CC 3 in cortex of the 4 strains at P14. Images at bottom right corner of each are from corresponding controls (same magnification). Images are taken from the same regions as in Figure 2. Images shown are from female mice. Except for DBAs, images shown are representative of at least 2 males and 2 females per strain (for total $N$ values killed at these time points, see Fig. $2 E$ ). For male-female comparison in 12951 mice, see Figure 4. Scale bar, $200 \mu \mathrm{m}$, for all except high-magnification insets depicting single cells.

were intensely stained with hematoxylin. These "ICCs" were found in many brain regions but were largest and most numerous in the thalamus, hippocampus, and cerebellum (Fig. $8 B-E$ ). Calcifications were rare in rostral cortex and striatum (Fig. $8 F$ ), but often extensive in caudal cortex (Fig. $8 A, G$ ). Scattered small calcifications were present in the brainstem of some B6 and 129S1 mice (Fig. $8 H$ ). Considerable variation was encountered between strains; ICCs were small and infrequent in FVB and DBA mice, and widespread in B6 mice of both sexes. ZIKV-treated female mice of the 129S1 strain had the greatest load of ICCs, whereas males had significantly less. Although the vast majority of ICCs were located in gray matter, occasional calcification of white matter tracts was observed. Notably, all ZIKV-treated 129S1 females had bilateral calcifications of the fasciculus retroflexus (Fig. $8 C^{\prime}$ arrow), which was also observed in some B6 mice. However, none of these mice had calcified habenulae. One 129S1 female also had a calcification in the anterior commissure (Fig. 8I), and another had two small ICCs in the corpus callosum (Fig. 8J, arrow). The use of a nonsuppressive silver stain to reveal axons (Lund and Westrum, 1966) showed that the ICCs disrupted the normal connectivity in many brain regions. Immunostaining for GFAP revealed extensive astrocytic reaction around the calcifications (Fig. $8 K, L$ ) but the absence of glial activation (both astocytes and microglia) elsewhere in the brain. Calcifications were never observed in control mice.

We compared the occurrence of behavioral deficits in adulthood with the number and size of ICCs in the brains of the two most affected strains (B6 and 129S1). A semiquantitative analysis of ICCs in these two strains revealed a significant correlation between total ICC burden and open field activity (Spearman correlations; B6 mice, $\rho=0.824, n=20, Z=3.590, p=0.0003$; for 129S1 mice, $\rho=0.625, n=17, Z=2.500, p=0.0124$; Fig. $8 P$ ). ICC burden also correlated with the time spent in the open area of the elevated zero maze (for B6 mice, $\rho=0.615, n=19, Z=2.608$, $p=0.0091$; for 129 S1 mice, $\rho=0.541, n=15, Z=2.026, p=$ 0.0428 ). Interestingly, not all of the most hyperactive ZIKVtreated mice were impaired on the rotarod, and the amount of calcifications in the cerebellum appeared to differentiate those performing poorly (Fig. $8 \mathrm{M}-\mathrm{O}$ ). We therefore examined the relationship between rotarod performance and the ICC score specifically in the cerebellum (Fig. 8Q) and found a significant negative correlation $(\rho=-0.721, n=20, Z=-4.325, p<$ $0.0001)$. Because control males of the $129 S 1$ strain performed poorly on the rotarod, males were excluded from this analysis. In general, male 129S1 mice had very few ICCs, consistent with their relative lack of behavioral deficits. 


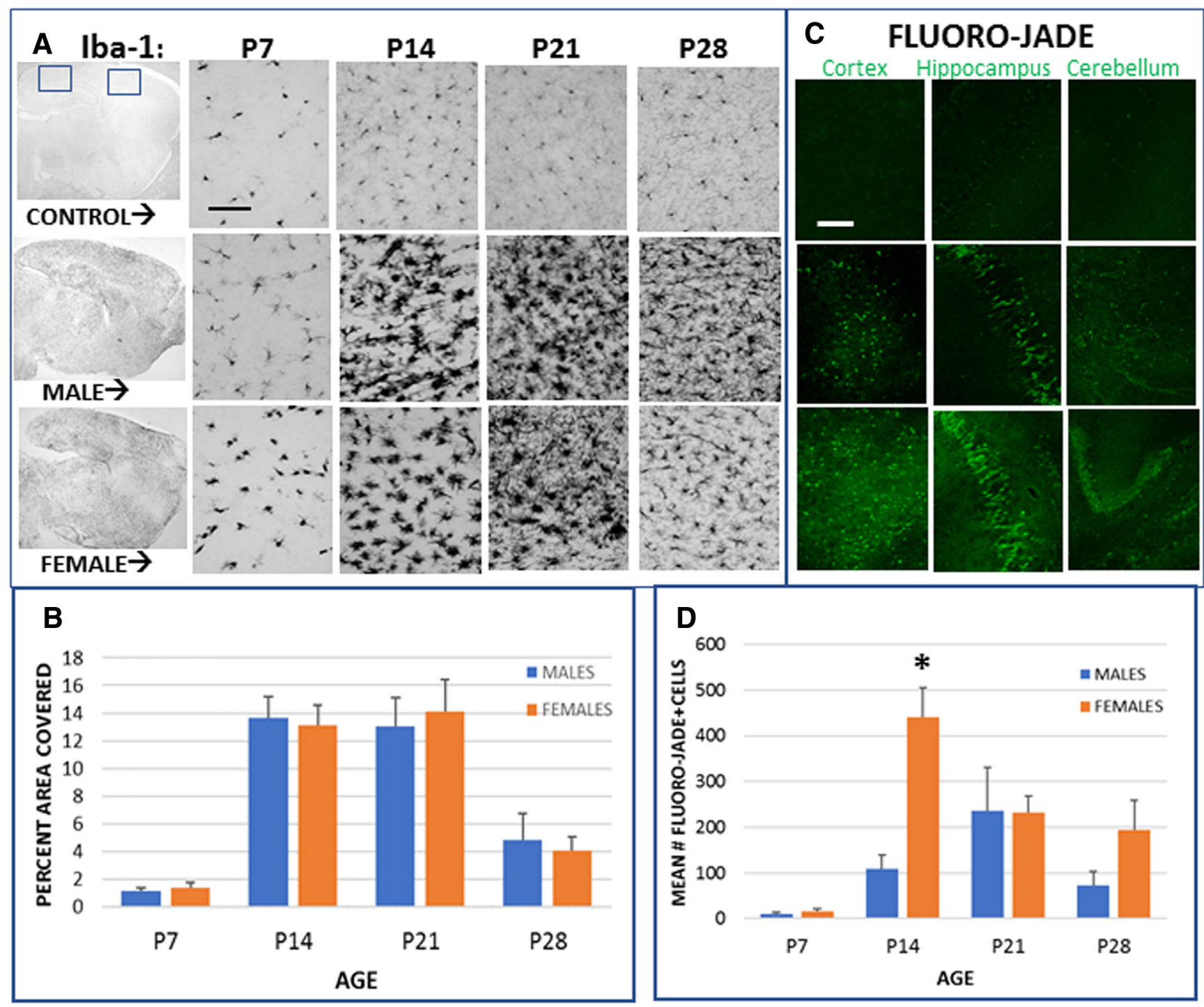

Figure 4. Sex differences in microglial activation and cell death in ZIKV-treated 12951 mice. A, Immunostaining for Iba-1 in representative brain sections from male and female ZIKV-treated 12951 mice at P7, P14, P21, and P28, compared with controls. Low-magnification images in left column represent the widespread increase in lba-1 immunostaining seen in the ZIKV-treated brains. Top, Boxes represent the location of images collected for the quantification in $\boldsymbol{B}$. High-magnification images are from caudal cortex. $\boldsymbol{B}$, Quantification of microglial staining in ZIKV-treated male and female 12951 cortex as a function of age. Bars indicate the mean percentage of area covered with Iba- 1 immunostaining ( \pm SE); $N$ values, 4 or 5 at $P 7,7$ or 8 at $P 14,6$ each at $P 21,3$ each at $P 28$. Levels in control brains were $<1.5 \%$ (data not shown). C, FJ-B staining in cortex, hippocampus, and cerebellum of representative P14 male and female ZIKV-treated 12951 mice compared with controls. $D$, Quantification of the number of FJ-B ${ }^{+}$cells in cortex as a function of age; $N$ values, 3 each at P7, 4 each at P14 and P21, 5 each at P28. No FJ ${ }^{+}$cells were seen in controls. ${ }^{*} t=4.653, p=0.0035$ at P14. Scale bars, in $A$ and $C 100 \mu \mathrm{m}$.

\section{Discussion}

Since the Zika outbreak of 2016, research has focused on reproducing microcephaly in animal models (Morrison and Diamond, 2017). This work, primarily done in immunocompromised mice that lack the interferon- $\alpha$ receptor, demonstrated that early gestational infection (up to embryonic day [E] 10) was most likely to result in microcephaly (Miner et al., 2016). However, ZIKV infection later in pregnancy, when the brain is undergoing a massive increase in neurite outgrowth and synaptogenesis, may be more relevant to neurobehavioral disorders linked to brain connectivity defects, such as attention deficit hyperactivity disorder, autism spectrum disorder, and schizophrenia. The neonatal period in rodents corresponds to the third trimester in humans, and infection during this time would be expected to target laterdeveloping brain regions. Moreover, because of the immaturity of the immune system at birth, newborn mice cannot clear the virus, thus avoiding the necessity of using mice with targeted mutations of the interferon- $\alpha$ receptor. Studies demonstrating that neonatal mice are sensitive to ZIKV infection (Manangeeswaran et al., 2016; van den Pol et al., 2017) have introduced the possibility of evaluating strain-dependent differences in susceptibility in immunocompetent mice. A recent study compared ZIKV pathogenesis in four diverse mouse strains after neonatal injection but used a viral dose that resulted in $100 \%$ mortality by $15 \mathrm{~d}$ after infection (Li et al., 2018). Here we report on the effects of neonatal ZIKV infection with a moderate dose that produces transient symptoms during the first few weeks after injection, to begin to correlate early susceptibility, persistent anatomical pathologies, and behavioral deficits in adulthood, in four strains of mice at different arms of the mouse family tree.

Although ZIKV infection could be demonstrated in all four strains in our study, the extent to which the virus propagated 
within the brain differed greatly. In those strains most symptomatic during the 1 month period after P1 injection (129S1 and B6), the viral load increased from P7 to P14. Cerebral cortex, thalamus, hippocampus, and cerebellum displayed considerable infection. The time course of the glial response to the virus also differed considerably between strains. Although conclusions are limited by the small number of mice examined during this time frame, it appears that the intensity and duration of the inflammatory response corresponded with the occurrence of symptoms during the acute phase of infection (more so in 129S1 and B6 mice), as well as with the damage that triggered the formation of calcifications (also more extensive in 129S1 and B6 mice). The use of multiple divergent, but generally immunocompetent, mouse strains will permit a comprehensive examination of the components of the host immune response that are associated with the pathology that develops after neonatal ZIKV exposure. Genetic differences that underlie divergent immune responses in response to several infectious agents have been identified (Sellers et al., 2012). Elucidation of these factors, in conjunction with the characterization of cytokines involved in the Zika response in the human (Azevedo et al., 2018), will support the development of immunocompetent mouse models that can be used to generate strategies to intervene in the pathogenic process.

ICCs are a common neuropathological finding in babies born to ZIKV-exposed women. Visualized by brain imaging techniques, these are most commonly located in cerebral cortex, basal ganglia, and the interface between gray and white matter (Melo et al., 2016; Mlakar et al., 2016; Aragao et al., 2017). A more thorough description of their size and distribution within the brain has come from postmortem analyses of stillbirths and aborted fetuses (Mlakar et al., 2016; Chimelli et al., 2017; Azevedo et al., 2018). Calcifications have been reported to occur after other in utero infections, such as with cytomegalovirus (Livingston et al., 2014). Although the mechanism leading to the formation of calcifications within the brain is still unclear, it is widely believed that they represent a pathological outcome of persistent inflammation, oxidative stress, and necrosis, often occurring in response to infectious agents (Livingston et al., 2014).

ICCs were a common finding in the brains of ZIKV-treated mice examined at 3-4 months of age, when the total ICC burden correlated with the hyperactivity and impulsivity phenotype seen in B6 and 129S1 mice, and cerebellar ICC burden was predictive of
B6
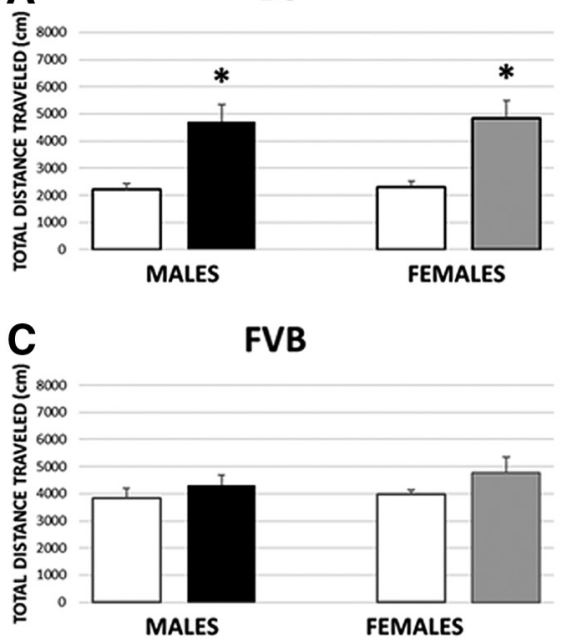
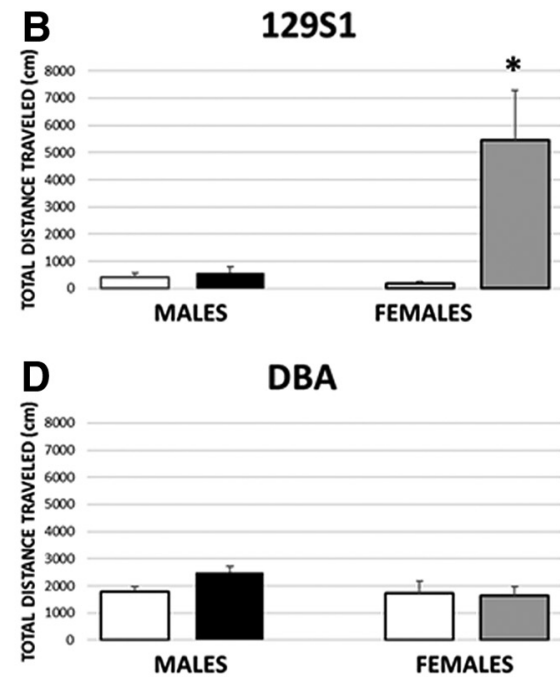

Figure 5. Open field activity. Mean total distance traveled ( $\mathrm{cm}+\mathrm{SEM})$ in the open field, for postnatally ZIKV-treated and control male and female mice from four different inbred strains. White bars represent controls. Black or gray bars represent ZIKV. Data were analyzed for each strain separately, using a two-way ANOVA (treatment $\times$ sex), followed by Tukey post hoc tests. $A$, For the B6 strain, there was a significant main effect of treatment $\left(F_{(1,48)}=24.596, p<0.0001\right)$. ZIKV-infected B6 male and female mice displayed hyperactivity relative to their corresponding (strain/treatment/sex) controls. $\boldsymbol{B}$, For the 12951 strain, there were significant effects of treatment $\left(F_{(1,34)}=7.509, p=0.0097\right)$ and $\operatorname{sex}\left(F_{(1,34)}=5.561, p=0.0243\right)$, as well as a significant treatment $\times$ sex interaction $\left(F_{(1,34)}=6.723, p=0.0139\right)$. There was no effect of treatment in the $\mathrm{FVB}(p=0.2243 ; C)$ and DBA $(p=0.3745 ; D)$ strains. ${ }^{*} p<0.05$, compared with controls of the same strain, treatment, and sex. $N$ values are as follows: $\mathrm{B} 6$ males (12 C, 15 ZIKV), B6 females (12 C, 13 ZIKV), $129 S 1$ males ( 9 C, 10 ZIKV), $129 S 1$ females ( 9 C, 10 ZIKV), FVB males (10 C, 10 ZIKV), FVB females (10 C, 19 ZIKV), DBA males (6C, 10 ZIKV), DBA females (8C, 6 ZIKV). C, Controls.
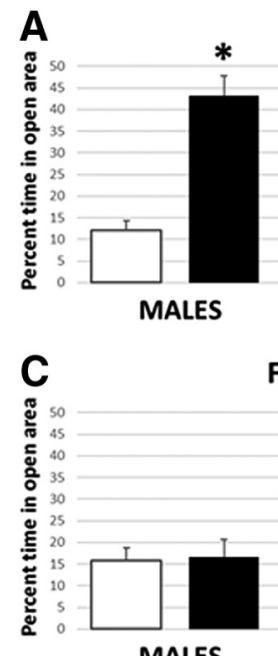

MALES
B6

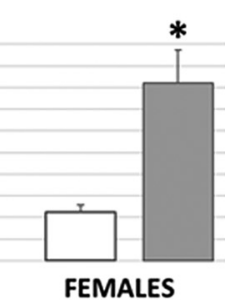

FVB

Figure 6. Elevated zero maze. Mean time (+ SEM) spent in the open portions of the maze, for postnatally ZIKV-treated male and female mice from four inbred strains. White bars represent controls. Black or gray bars represent ZIKV. Data were analyzed for each strain separately, using a two-way ANOVA (treatment $\times$ sex), followed by Tukey post hoc tests. $A$, In the B6 strain, there was a significant main effect of treatment $\left(F_{(1,48)}=40.039, p<0.0001\right)$. Male and female B6 mice infected with ZIKV spent more time in the open portions of the maze than did their corresponding (strain/treatment/sex) control groups. $\boldsymbol{B}$, For the 129S1 strain, there was a significant main effect of $\operatorname{sex}\left(F_{(1,34)}=6.44, p=0.0159\right)$ and a significant treatment $\times$ sex interaction $\left(F_{(1,34)}=4.896\right.$, $p=0.0337)$. C, For FVB mice, there was a main effect of $\operatorname{sex}\left(F_{(1,46)}=4.333, p=0.043\right)$ but not treatment $(p=0.262$; treatment $\times$ sex interaction, $p=0.3449)$. $D$, For DBA mice, there was a main effect of $\operatorname{sex}\left(F_{(1,31)}=6.03, p=0.0199\right)$ but not treatment $(p=0.2802$; treatment $\times$ sex interaction, $p=0.7107)$. ${ }^{*} p<0.05$, compared with controls of the same strain, treatment, and sex. N values are as follows: B6 males (12 C, 15 ZIKV), B6 females (12 C, 13 ZIKV), 129 S1 males (10 C, 9 ZIKV), 12951 females ( 9 C, 10 ZIKV), FVB males (10 C, 10 ZIKV), FVB females (11C, 19 ZIKV), DBA males ( 9 C, 10 ZIKV), DBA females ( 9 C, 6 ZIKV). c, Controls. motor deficits in the rotarod test. Few previous studies in mice have found ICCs, perhaps because the mice were killed at too young an age, ZIKV exposure occurred during early gestation, or immunocompromised mice were used. However, a recent study 
A

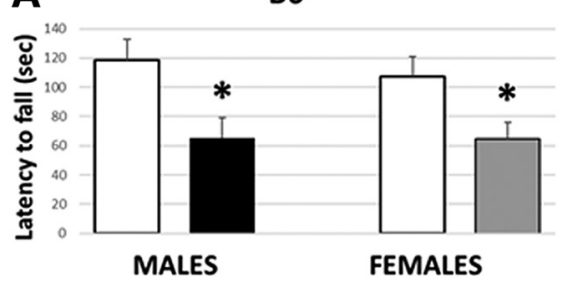

C

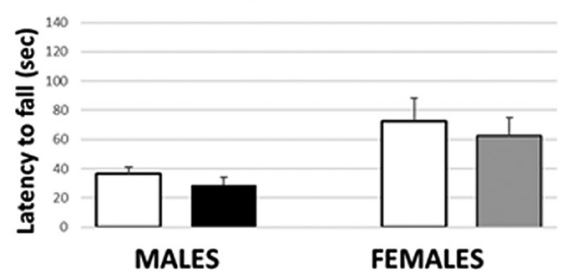

B

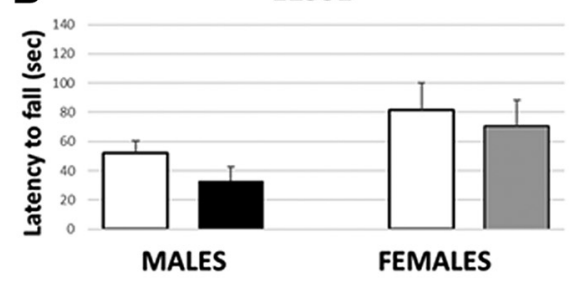

D

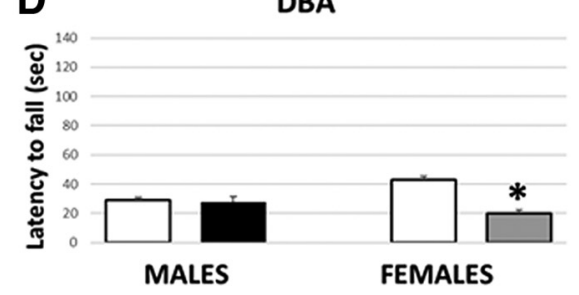

Figure 7. Rotarod. Mean latency to fall ( + SEM), for postnatally ZIKV-treated male and female mice from four different inbred strains. White bars represent controls. Black or gray bars represent ZIKV. Data were analyzed for each strain separately, using a two-way ANOVA, followed by Tukey post hoc tests. $A$, In the B6 strain, there was a significant main effect of treatment $\left(F_{(1,48)}=\right.$ $12.415, p=0.0009)$. Male and female B6 mice infected with ZIKV displayed shorter latencies to fall than did their corresponding (strain/treatment/sex) control groups. $\boldsymbol{B}$, For the 12951 strain, there was a significant main effect of $\operatorname{sex}\left(F_{(1,32)}=5.435, p=\right.$ $0.0262)$, but treatment did not have an effect on performance $(p=0.3018)$. C, Although male FVB mice displayed shorter latencies to fall off the rod than did FVB females $\left(F_{(1,40)}=7.031, p=0.0114\right)$, treatment had no effect on performance in this strain $(p=$ $0.5053)$. $D$, For the $D B A$ strain, there was a significant main effect of treatment $\left(F_{(1,27)}=17.453, p=0.0003\right)$ and a significant interaction between treatment $\times \operatorname{sex}\left(F_{(1,27)}=13.115, p=0.0012\right) .{ }^{*} p<0.05$, compared with controls of the same strain, treatment, and sex. $N$ values are as follows: B6 males (11 C, 15 ZIKV), B6 females (12 C, 14 ZIKV), 129 S1 males (9 C, 9 ZIKV), 129 S1 females ( 9 C, 9 ZIKV), FVB males (8 C, 9 ZIKV), FVB females (8C, 19 ZIKV), DBA males ( 9 C, 10 ZIKV), DBA females (6 C, 6 ZIKV). C, Controls.

reported ICCs in the brains of B6 mice infected at E15 via intrauterine injection (Cui et al., 2017). Interestingly, in our study ZIKV-infected neurons were most numerous in the cortex in mice killed at P7-P21, yet the calcifications observed in the brains of adult mice were largest and most numerous in the thalamus, hippocampus, and cerebellum. Thus, the number of ZIKVinfected neurons in a region did not fully predict regions with subsequent calcification. On the other hand, the resulting inflammation, when excessive and prolonged, could produce tissue injury that includes calcifications.

ZIKV can infect both neurons and glia (Bhatnagar et al., 2017; van den Pol et al., 2017). Although we did not specifically identify infected cells as neuronal, they appeared phenotypically to be neurons. ZIKV was not found in white matter, and ICCs rarely formed in white matter. One notable exception was the fasciculus retroflexus, a tract that contains axons of neurons projecting from the habenula to the interpeduncular nucleus and other brainstem nuclei (Murphy et al., 1996). Bilateral calcifications were found in the fasciculus retroflexus of all 129S1 females. Lesions of the fasciculus retroflexus have been shown to result in hyperactivity and increased impulsiveness (Murphy et al., 1996; Kobayashi et al., 2013), and possibly to a greater propensity for addiction (Ellison, 2002). Thus, our findings raise the possibility of future issues with drug addiction that could emerge in the developmentally ZIKV-exposed population.

The behavioral outcomes of neonatal ZIKV infection in our mice appeared most similar to the hyperactivity and impulsivity observed in attention deficit hyperactivity disorder. In the 129S1 strain, noted for its "hypoactive anxious phenotype" (Kalueff and Tuohimaa, 2005), some ZIKV-exposed females displayed profound hyperactivity in the open field, reaching scores $>10,000$, compared with the control mean $<200$. These same females displayed no anxiety about entering the open portions of the elevated zero maze, frequently immediately running out into the open in a way that could be considered "impulsive." In obvious contrast, controls usually remained in the enclosed portion for the entire trial. Individual differences in the behavioral consequences of developmental ZIKV infection were found to be related to the development of ICCs in the brains of susceptible mouse strains.

A remarkable sex difference was the lack of behavioral deficits and neuropathology in 129S1 males, even though their female littermates were the most profoundly affected of all mice. Interestingly, most studies have found males to be more susceptible to early life immune challenges than are females (Hanamsagar and Bilbo, 2016). Sex differences in microglial numbers and chemokine expression during critical developmental periods (Schwarz et al., 2012) may contribute to sexually dimorphic responses to infection early in life. We found no evidence for increased ZIKV levels in female 129S1 mice compared with their male counterparts, and no greater microglial activation in the brain. Nevertheless, greater cell death was observed at P14 in females compared with males. A more complete analysis of the tissue inflammatory response to ZIKV will be necessary to uncover the neuropathological events that trigger greater necrosis and buildup of calcifications in the brains of female mice of this strain. A recent study using a higher dose of ZIKV in a different mouse strain (Swiss mice) found females to be more affected in terms of social behavior, whereas males were more impaired on the rotarod (Nem de Oliveira Souza et al., 2018). Although sex differences in the neurobehavioral consequences of developmental ZIKV infection in humans have not yet been reported, conditions, such as attention deficit hyperactivity disorder and impulsive behaviors, may emerge when the current population of children exposed to ZIKV in utero reaches 5-6 years of age. Whereas these neurobehavioral disorders are more common in males of the general population, they may prove more common in ZIKV-exposed females.

The total burden of developmental ZIKV exposure in the pediatric population has yet to be determined (Kapogiannis et al., 2017). Studies aimed at deciphering the genetic factors involved in susceptibility or resistance in divergent immunocompetent strains, as used here, will help elucidate the extent to which host genetics impacts ZIKV-induced pathology. Infection at different critical periods of brain development is also likely to result in different patterns of calcifications and other pathologies, and thus different sets of behavioral abnormalities. Moreover, to the extent that early-life infection with ZIKV may reprogram the immune system in vulnerable individuals (Bilbo and Schwarz, 2009), leading to chronic or exaggerated microglial activation in response to immune challenges later in life, susceptibility to neurological disorders in this population may extend well beyond development. 

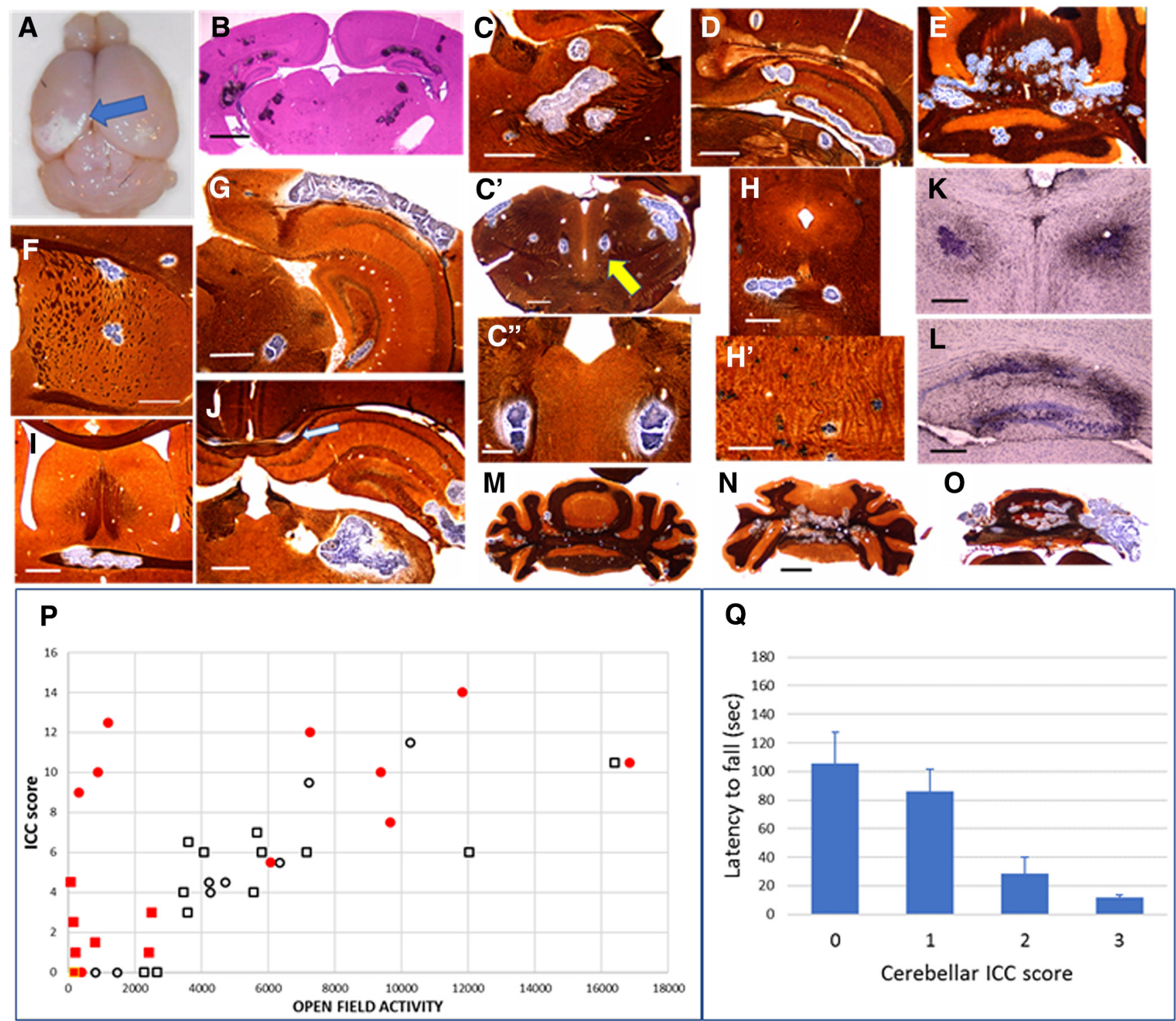

Figure 8. ICCs. A, Large calcification visible on the surface of a 12951 brain. B, Calcifications visible after H\&E staining. C $-J$, Calcifications stand out after a combination of hematoxylin and nonsuppressive silver staining in the following: $\boldsymbol{C}$, thalamus (arrow in $\boldsymbol{C}^{\prime}$ points to bilateral calcified fasciculi retroflexus, at higher magnification in $\boldsymbol{C}^{\prime \prime}$, different mouse), $\boldsymbol{D}$, hippocampus, $\boldsymbol{E}$, cerebellum, $\boldsymbol{F}$, striatum and cortex, $\boldsymbol{G}$, caudal cortex, $\boldsymbol{H}, \boldsymbol{H}^{\prime}$, brainstem, $\boldsymbol{I}$, anterior commissure, and $\boldsymbol{J}$, small calcifications in caudal corpus callosum (arrow) in mouse with large thalamic and hippocampal ICCS. $\boldsymbol{K}, \boldsymbol{L}$, GFAP immunostaining (black) reveals astrogliosis that persists around the ICCs in $(\boldsymbol{K})$ septum and $(\boldsymbol{L})$ hippocampus. $\boldsymbol{M}, \boldsymbol{N}$, Cerebella of two very hyperactive 12951 female sibs, one of whom did very well on the rotarod $(\boldsymbol{M})$, and the other $(\boldsymbol{N})$ did poorly. $\mathbf{0}$, Extremely calcified cerebellum of a B6 mouse that was still mildly ataxic at the time of rotarod testing and could not stay on the rod. Scale bars: $500 \mu \mathrm{m}$ for all, except $\boldsymbol{C}^{\prime \prime}, \boldsymbol{H}^{\prime}, \boldsymbol{K}, \boldsymbol{L}(200 \mu \mathrm{m})$ and $\boldsymbol{M}-\mathbf{O}(\boldsymbol{N}, 1 \mathrm{~mm}) . \boldsymbol{P}$, Correlation between ICC score (for quantification, see Materials and Methods) and open field activity (total distance traveled) for individual B6 and 12951 mice. Open symbols represent B6 mice. Filled symbols represent 12951 mice. Squares represent males. Circles represent females. For B6 mice, $\rho=0.824, n=20, Z=3.59, p=0.0003$; for 12951 mice, $\rho=0.625, n=17, Z=2.500, p=0.0124$. Q, Mean rotarod scores (latency to fall) of male and female B6 mice and female 12951 mice, grouped according to the severity of cerebellar ICCS. A score of 1 was assigned when large or numerous small ICCs were present, 2 when ICCs occupied a large part (up to $50 \%$ ) of cerebellum in any one section, and a score of 3 was given when the cerebellum was nearly full with ICCS. A larger cerebellar ICC score was predictive of poor performance on the rotarod $(\rho=-0.721, n=20, Z=$ $-4.325, p<0.0001)$.

\section{References}

Aragao M, Holanda AC, Brainer-Lima AM, Petribu NC, Castillo M, van der Linden V, Serpa SC, Tenório AG, Travassos PT, Cordeiro MT, Sarteschi C, Valenca MM, Costello A (2017) Nonmicrocephalic infants with congenital Zika syndrome suspected only after neuroimaging evaluation compared with those with microcephaly at birth and postnatally: how large is the Zika virus "iceberg? AJNR Am J Neuroradiol 38:1427-1434.

Azevedo RS, de Sousa JR, Araujo MT, Martins Filho AJ, de Alcantara BN, Araujo FM, Queiroz MG, Cruz AC, Baldez Vasconcelos BH, Chiang JO, Martins LC, Casseb LM, da Silva EV, Carvalho VL, Baldez Vasconcelos BC, Rodrigues SG, Oliveira CS, Quaresma JA, Vasconcelos PF (2018) In situ immune response and mechanisms of cell damage in central nervous system of fatal cases microcephaly by Zika virus. Sci Rep 8:1.
Bhatnagar J, Rabeneck DB, Martines RB, Reagan-Steiner S, Ermias Y, Estetter LB, Suzuki T, Ritter J, Keating MK, Hale G, Gary J, Muehlenbachs A, Lambert A, Lanciotti R, Oduyebo T, Meaney-Delman D, Bolaños F, Saad EA, Shieh WJ, Zaki SR (2017) Zika virus RNA replication and persistence in brain and placental tissue. Emerg Infect Dis 23:405-414.

Bilbo SD, Schwarz JM (2009) Early-life programming of later-life brain and behavior: a critical role for the immune system. Front Behav Neurosci 3:14.

Chimelli L, Melo AS, Avvad-Portari E, Wiley CA, Camacho AH, Lopes VS, Machado HN, Andrade CV, Dock DC, Moreira ME, Tovar-Moll F, Oliveira-Szejnfeld PS, Carvalho AC, Ugarte ON, Batista AG, Amorim MM, Melo FO, Ferreira TA, Marinho JR, Azevedo GS, et al. (2017) The 
spectrum of neuropathological changes associated with congenital Zika virus infection. Acta Neuropathol 133:983-999.

Coyne CB, Lazear HM (2016) Zika virus: reigniting the TORCH. Nat Rev Microbiol 14:707-715.

Cui L, Zou P, Chen E, Yao H, Zheng H, Wang Q, Zhu JN, Jiang S, Lu L, Zhang J (2017) Visual and motor deficits in grown-up mice with congenital Zika virus infection. EBioMedicine 20:193-201.

Ellison G (2002) Neural degeneration following chronic stimulant abuse reveals a weak link in brain, fasciculus retroflexus, implying the loss of forebrain control circuitry. Eur. Neuropsychopharmacol 12:287-297.

Fernandes NC, Nogueira JS, Réssio RA, Cirqueira CS, Kimura LM, Fernandes KR, Cunha MS, Souza RP, Guerra JM (2017) Experimental Zika virus infection induces spinal cord injury and encephalitis in newborn swiss mice. Exp Toxicol Pathol 69:63-71.

Hanamsagar R, Bilbo SD (2016) Sex differences in neurodevelopmental and neurodegenerative disorders: focus on microglial function and neuroinflammation during development. J Steroid Biochem Mol Biol 160: 127-133.

Honein MA, Dawson AL, Petersen EE, Jones AM, Lee EH, Yazdy MM, Ahmad N, Macdonald J, Evert N, Bingham A, Ellington SR, Shapiro-Mendoza CK, Oduyebo T, Fine AD, Brown CM, Sommer JN, Gupta J, Cavicchia P, Slavinski S, White JL, et al. (2017) Birth defects among fetuses and infants of US women with evidence of possible Zika virus infection during pregnancy. JAMA 317:59-68.

Kalueff AV, Tuohimaa P (2005) Contrasting grooming phenotypes in three mouse strains markedly different in anxiety and activity (129S1, BALB/c and NMRI). Behav Brain Res 160:1-10.

Kapogiannis BG, Chakhtoura N, Hazra R, Spong CY (2017) Bridging knowledge gaps to understand how Zika virus exposure and infection affect child development. JAMA Pediatr 171:478-485.

Kobayashi Y, Sano Y, Vannoni E, Goto H, Suzuki H, Oba A, Kawasaki H, Kanba S, Lipp HP, Murphy NP, Wolfer DP, Itohara S (2013) Genetic dissection of medial habenula-interpedencular nucleus pathway function in mice. Front Behav Neurosci 7:17-36.

Lanciotti RS, Kosoy OL, Laven JJ, Velez JO, Lambert AJ, Johnson AJ, Stanfield SM, Duffy MR (2008) Genetic and serologic properties of Zika virus associated with an epidemic, Yap State, Micronesia, 2007. Emerg Infect Dis 14:1232-1239.

Lazear HM, Govero J, Smith AM, Platt DJ, Fernandez E, Miner JJ, Diamond MS (2016) A mouse model of Zika virus pathogenesis. Cell Host Microbe 19:720-730.

Li C, Xu D, Ye Q, Hong S, Jiang Y, Liu X, Zhang N, Shi L, Qin CF, Xu Z (2016) Zika virus disrupts neural progenitor development and leads to microcephaly in mice. Cell Stem Cell 19:593-598.

Li S, Armstrong N, Zhao H, Hou W, Liu J, Chen C, Wan J, Wang W, Zhong C, Liu C, Zhu H, Xia N, Cheng T, Tang Q (2018) Zika virus fatally infects wild type neonatal mice and replicates in central nervous system. Viruses 10:49.

Livingston JH, Stivaros S, Warren D, Crow YJ (2014) Intracranial calcification in childhood: a review of aetiologies and recognizable phenotypes. Devel Med Child Neurol 56:612-626.
Lund RD, Westrum LE (1966) Neurofibrils and the Nauta method. Science 151:1397-1399.

Manangeeswaran M, Ireland DD, Verthelyi D (2016) Zika (PRVABC59) infection is associated with $\mathrm{T}$ cell infiltration and neurodegeneration in CNS of immunocompetent C57 Bl/6 mice. PLoS Pathog 12:e1006004.

Melo AS, Aguiar RS, Amorim MM, Arruda MB, Melo FO, Ribeiro ST, Batista AG, Ferreira T, Dos Santos MP, Sampaio VV, Moura SR, Rabello LP, Gonzaga CE, Malinger G, Ximenes R, de Oliveira-Szejnfeld PS, TovarMoll F, Chimelli L, Silveira PP, Delvechio R, et al. (2016) Congenital Zika virus infection: beyond neonatal microcephaly. JAMA Neurol 73:1407-1416.

Miner JJ, Cao B, Govero J, Smith AM, Fernandez E, Cabrera OH, Garber C, Noll M, Klein RS, Noguchi KK, Mysorekar IU, Diamond MS (2016) Zika virus infection during pregnancy in mice causes placental damage and fetal demise. Cell 165:1081-1091.

Mlakar J, Korva M, Tul N, Popovoc M, Poljsak-Prijatelj M, Mraz J, Kolenc M, Resman Rus K, Vesnaver Vipotnik T, Fabjan Vodusek V, Vizjak A, Pizem J, Petrovec M, Avsic Zupanc T (2016) Zika virus associated with microcephaly. N Engl J Med 374:951-958.

Morrison TE, Diamond MS (2017) Animal models of Zika virus infection, pathogenesis, and immunity. J Virol 91:e00009-e00017.

Murphy CA, DiCamillo AM, Haun F, Murray M (1996) Lesion of the habenular efferent pathway produces anxiety and locomotor hyperactivity in rats: a comparison of the effects of neonatal and adult lesions. Behav Brain Res 81:43-52.

Nem de Oliveira Souza I, Frost PS, Franca JV, Nascimento-Viana JB, Neris RL, Freitas L, Pinheiro DJ, Nogueira CO, Neves G, Chimelli L, De Felice FG, Cavalheiro EA, Ferreira ST, Assuncao-Miranda I, Figueiredo CP, Da Poian AT, Clarke JR (2018) Acute and chronic neurological consequences of early-life Zika virus infection in mice. Sci Transl Med 10:eaar2749.

Petkov PM, Ding Y, Cassell MA, Zhang W, Wagner G, Sargent EE, Asquith S, Crew V, Johnson KA, Robinson P, Scott VE, Wiles MV (2004) An efficient SNP system for mouse genotype scanning and elucidating strain relationships. Genome Res 14:1806-1811.

Rossi SL, Tesh RB, Azar SR, Muruato AE, Hanley KA, Auguste AJ, Langsjoen RM, Paessler S, Vasilakis N, Weaver SC (2016) Characterization of a novel murine model to study Zika virus. Am J Trop Med Hyg 94: 1362-1369.

Schmued LC, Hopkins KJ (2000) Fluoro-jade B: a high affinity fluorescent marker for the localization of neuronal degeneration. Brain Res 874: $123-130$.

Schwarz JM, Sholar PW, Bilbo SD (2012) Sex differences in microglial colonization of the developing rat brain. J Neurochem 120:948-963.

Sellers RS, Clifford CB, Treuting PM, Brayton C (2012) Immunological variation between inbred laboratory mouse strains: points to consider in phenotyping genetically immunomodified mice. Vet Pathol 49:32-43.

Shepherd JK, Grewal SS, Fletcher A, Bill DJ, Dourish CT (1994) Behavioural and pharmacological characterisation of the elevated "zero-maze" as an animal model of anxiety. Psychopharmacology (Berl) 116:56-64.

van den Pol AN, Mao G, Yang Y, Ornaghi S, Davis JN (2017) Zika virus targeting in the developing brain. J Neurosci 37:2161-2175. 